Gut, 1980, 21, 177-180

\title{
Separation of the gut hormone endocrine-cell storage granules of human jejunum using analytical subcellular fractionation
}

\author{
M G BRYANT, J DAWSON, S R BLOOM,* AND T J PETERS \\ From the Department of Medicine, Royal Postgraduate Medical School, London \\ and Division of Clinical Cell Biology, Clinical Research Centre, Harrow, Middlesex
}

\begin{abstract}
SUMMARY Analytical subcellular fractionation techniques in combination with specific radioimmunoassays have been used to investigate the properties of the hormone-containing granules in human jejunal biopsy specimens. After gentle homogenisation, for all hormones except VIP, over $90 \%$ of the immunoreactivity was released in intact granules into the post-nuclear supernatant. Approximately $50 \%$ of the VIP immunoreactivity sedimented with the low speed pellet, probably reflecting the presence of this peptide in nerve fibres. The following hormone granules (equilibrium densities between parentheses) were separated by isopycnic centrifugation on the sucrose density gradients: VIP (1·17), motilin (1.20), and secretin (1.24). Gastrin and GIP granules were not resolved, both having the same modal density of $1.22 \mathrm{~g} / \mathrm{cm} .{ }^{3}$ This combination of procedures thus provides a new quantitative technique for studying the properties of the gastrointestinal hormone-containing granules, and should therefore be of value in investigating pathophysiological problems in a variety of gastrointestinal diseases.
\end{abstract}

With the development of accurate methods for measurement of gut hormones it has become apparent that there are characteristic abnormalities of the plasma gut hormone profile associated with various diseases of the human gastrointestinal tract. ${ }^{1}$ Very little information, however, is as yet available about such fundamental aspects as the synthesis, storage, and mode of secretion of these hormones at the cellular level. Using the combined techniques of specific immunocytochemistry and electron microscopy it is now possible to identify the cells of origin of the gut hormones and recognise the hormone storage granules characteristic of each endocrine cell-type. ${ }^{2}$ However, while such studies give information as to the relative size and appearance of the granules, quantitative studies are not possible.

It has recently been shown that analytical subcellular fractionation procedures permit the quantitative assessment of the properties of individual subcellular organelles both in healthy and diseased tissues. ${ }^{3}$ The development of a suitable single-step fractionation technique, coupled with highly sensi-

*Address for correspondence: Dr S R Bloom, Department of Medicine, Royal Postgraduate Medical School, Du Cane Road, London W12 OHS

Received for publication 16 October 1979 tive organelle-marker enzyme assays, has further allowed analytical fractionation techniques to be applied successfully to human biopsies, even in the small quantities of tissue obtained by jejunal biopsy. ${ }^{4}$ The purpose of this present study is to evaluate the use of these fractionation procedures to investigate the physical properties of gut hormone storage granules.

\section{Methods}

ANALYTICAL SUBCELLULAR FRACTIONATION Jejunal biopsies were obtained with a Crosby capsule from patients undergoing routine investigation for possible gastrointestinal disease. The tissues used in this study were found to be entirely normal on histochemical examination. Approximately $5 \mathrm{mg}$ (wet weight) of biopsy material was collected in $3 \mathrm{ml}$ of ice cold sucrose solution $(0.3 \mathrm{~mol} / \mathrm{l})$ containing $1 \mathrm{mmol} / 1 \mathrm{Na}_{2}$ EDTA $\mathrm{pH} 7 \cdot 2$ and $20 \mathrm{~mol} / \mathrm{l}$ ethanol (SVE medium). The tissue was disrupted with 10 strokes of a loose-fitting (type A) pestle in a small Dounce homogeniser (Kontes Glass Co Vineland, NJ) and centrifuged at $800 \mathrm{~g}$ for 10 minutes. The pellet was resuspended in a further $2 \mathrm{ml}$ of SVE medium with three strokes of the pestle and recentrifuged. 
These post-nuclear supernatants (PNS fraction) were combined and the low speed pellet comprising nuclei, large brush-border fragments, and undisrupted cells (nuclear fraction) was resuspended in $2 \mathrm{ml}$ of SVE medium with a tight fitting (type B) pestle. Approximately $3.5 \mathrm{ml}$ of PNS fraction was layered onto $28 \mathrm{ml}$ of a sucrose density gradient extending linearly with respect to volume from a density of 1.05 to 1.28 , resting on a cushion of density 1.32 in an automatic zonal rotor. ${ }^{4}$ All solutions contained $1 \mathrm{mmol} / 1 \mathrm{Na}_{2}$ EDTA pH $7 \cdot 2$ and $20 \mathrm{mmol} / 1$ ethanol. The rotor was accelerated to $35000 \mathrm{rev} / \mathrm{min}$ and run for 35 minutes with an integrated force of $3.3 \times 10^{10} \mathrm{rad}^{2} \mathrm{sec}^{-1}$. The rotor was then slowed to $8000 \mathrm{rev} / \mathrm{min}$ for automatic unloading and collection of the gradient fractions. Some 15 fractions were collected into tared tubes, thoroughly mixed, reweighed and their density determined indirectly with an Abbe refractometer.

Aliquots of the gradient fraction were mixed with an equal volume of $0.2 \mathrm{~mol} / 1 \mathrm{HCl}$ to minimise proteolytic degradation of the hormones and kept deep frozen at $-20^{\circ} \mathrm{C}$ until radioimmunoassay of hormone content. Freezing and thawing of the gradient samples in $0.1 \mathrm{~mol} / 1 \mathrm{HCl}$ after fractionation released the granule-bound hormones for radioimmunoassay.

\section{RADIOIMMUNOASSAYS}

Full details of radioimmunoassays for the gut hormones motilin, ${ }^{6}$ gastrin, ${ }^{6}$ secretin, ${ }^{7}$ gastric inhibitory peptide (GIP), ${ }^{8}$ and vasoactive intestinal peptide (VIP) ${ }^{9}$ have been reported elsewhere. All assays, except that for gastrin, were developed to the pure natural porcine hormones. In the case of gastrin, synthetic human gastrin I (ICI) was used. Antibodies to each hormone were raised in rabbits with the peptide coupled to bovine serum albumin by carbodiimide condensation. All antisera were tested for specificity by addition of up to $2 \mathrm{nmol}$ per assay tube of all available gut hormones. In no case was any significant degree of cross-reactivity observed. The antibody dilutions routinely used and the assay sensitivities achieved are summarised in Table 1. VIP, secretin, motilin, and GIP were all radioactively labelled with the lactoperoxidase

Table 1 Antibody dilutions used and sensitivities achieved for the individual radioimmunoassays

\begin{tabular}{lll}
\hline Antiserum & $\begin{array}{l}\text { Final dilution } \\
\left(\times 10^{4}\right)\end{array}$ & $\begin{array}{l}\text { Assay sensitivity } \\
(\text { fmol })\end{array}$ \\
\hline Gastrin & 18 & 0.6 \\
Secretin & 28 & 0.4 \\
Motilin & 24 & 0.4 \\
VIP & 32 & 0.4 \\
GIP & 9.6 & 1.0 \\
\hline
\end{tabular}

technique,$^{108}$ whereas a modification of the chloramine T method was used for gastrin.11

Because the quantities of tissue used in this study were extremely small all assays were specially modified and optimised for small sample addition using a total reaction volume of $200 \mu$ l. Each centrifugation gradient fraction was assayed at three separate dilutions $(1 / 200,1 / 20$, and $1 / 4)$.

Protein content of the homogenates was assayed by the technique of Lowry et al. ${ }^{12}$ Protein in the subcellular fraction was assayed by the fluorimetric technique of Hiraoka and Glick.13 Bovine serum albumin (Sigma, London) was used as a standard.

\section{Results}

In all cases the immunoreactive hormone content of the sucrose density gradient fractions diluted in parallel fashion to the respective standard curves. Sucrose at concentrations found in the density gradient fractions was found to have no effect on the assays.

Table 2 Specific activity of hormones in total jejunal biopsy homogenates and percentage of hormonal immunoreactivity released by homogenisation procedure

\begin{tabular}{lll}
\hline & Specific activity & $\begin{array}{l}\text { Percentage hormonal } \\
\text { immunoreactivity in PNS }\end{array}$ \\
\hline Motilin & $4.0 \pm 0.9$ & $94.6 \pm 1.5$ \\
Secretin & $3.2 \pm 0.8$ & $97.0 \pm 0.8$ \\
VIP & $1.9 \pm 0.7$ & $56.6 \pm 1.0$ \\
GIP & $2.4 \pm 0.6$ & $98.4 \pm 0.7$ \\
Gastrin & $2.7 \pm 0.5$ & $98.9 \pm 0.4$ \\
\hline
\end{tabular}

Protein content of the biopsies was $2 \cdot 7 \pm 0.6 \mathrm{mg}$ (mean $\pm \mathrm{SEM}$ ) with $70.0 \pm 1.6 \%$ being recovered in the PNS fraction.

Table 2 shows the hormone concentrations in the biopsy extracts and the amount of immunoreactivity in the PNS fraction as a percentage of the total activity in the tissue homogenate. Whereas most of the hormonal immunoreactivity in the cases of gastrin, GIP, motilin, and secretin was recovered in the PNS fraction, considerable quantities of VIP immunoreactivity remained in the low speed pellet (nuclear fraction).

The Figure shows frequency-density histograms for the individual gut hormones and also for the protein content of the biopsies. In the case of VIP and secretin, each had distinct particulate components of immunoreactivity of model density 1.17 and 1.24 respectively with little or no immunoreactivity detectable in the soluble region of the gradient. The GIP and gastrin distribution patterns were similar, each having a small quantity of a soluble component and a well-defined granule component of modal density $1 \cdot 22$. Motilin had a distinct 


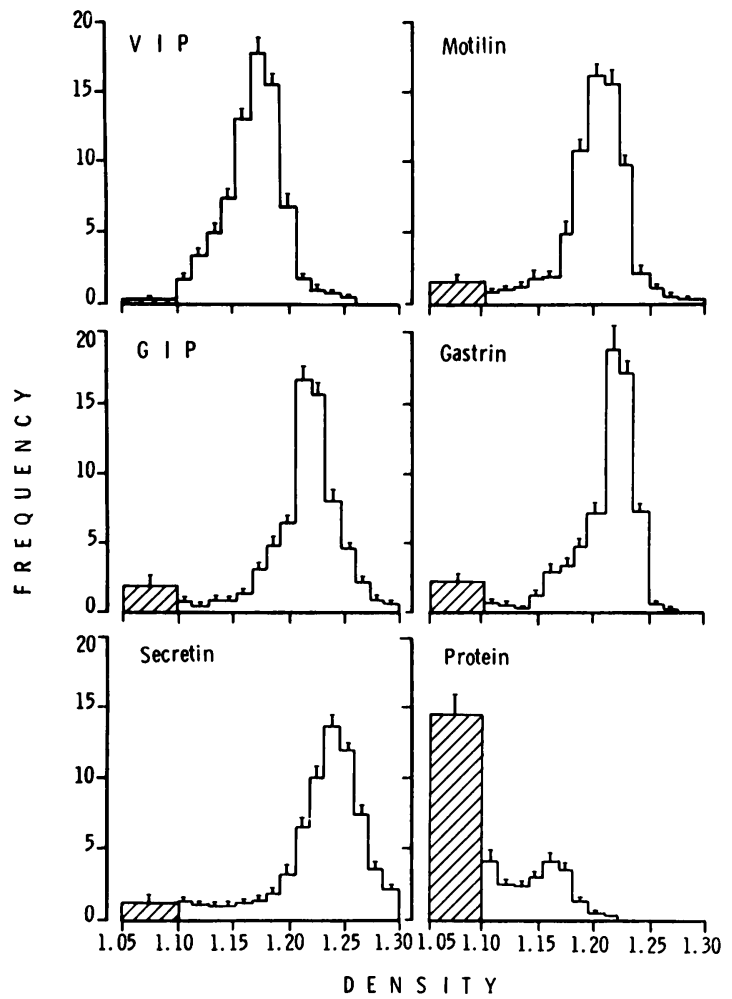

Figure Isopycnic centrifugation of $8000 \mathrm{~g}-\mathrm{min}$ supernatants from five jejunal biopsy homogenates. Graph shows frequency-density histograms for gastrointestinal hormones and for protein. Frequency (mean $\pm S E M$ ) is defined as the fraction of total recovered activity present in the subcellular fraction divided by the density span covered. The cross-hatched area represents, over an arbitrary abscissa interval, the activity remaining in the sample layer and is presumed to reflect soluble activity.

particulate component at a density of 1.20 with some activity remaining in the sample layer.

\section{Discussion}

This study is the first to report the separation of the various hormone-containing storage granules of the endocrine cells of the human gastrointestinal tract by zonal sucrose density gradient centrifugation. Both secretin ${ }^{14}$ and gastrin-like immunoreactivity ${ }^{15}$ have, however, previously been shown to be present in particulate structures by subcellular fractionation procedures. It would seem clear from the data presented here that a considerable difference exists in the density of the different hormone granule of the human jejunum and that for the most part they can be separated with ease. Only GIP and gastrin have granules of such similar density as to prevent clear separation under these conditions.

The conditions used here for the homogenisation of the biopsies and the subsequent intracellular fractionation appear to have been highly successful. In all cases, except for VIP, over $90 \%$ of the hormonal immunoreactivity was recovered from the post-nuclear supernatant fraction with little or no immunoreactivity being detectable in the low speed pellet, thus indicating that the cells were adequately disrupted to allow release of the hormone granules. Similarly, very little immunoreactivity was recovered in the low density 'soluble' region of the gradients, indicating that conditions were not so harsh as to cause significant disruption of the released granules. The presence of considerable quantities of VIP-like immunoreactivity in the low speed pellet could be explained by the fact that VIP occurs for the most part in fine nerve fibres and plexi both in the gut wall and mucosa. ${ }^{16-18}$ Thus the homogenisation conditions may not have been completely effective in the disruption of all the VIP-containing tissue. The VIP immunoreactivity seen here in the low speed pellets may thus reflect that present in nerve terminals, which would be expected to escape disruption under the conditions chosen and so would sediment with the larger cell debris.

There appears to be little correlation between the hormone granule densities reported here and the sizes of the granules determined by electron microscopy. Of those examined here, GIP granules in the human are the largest $(350 \mathrm{~nm})^{2}$ and intestinal gastrin granules the smallest $(180-190 \mathrm{~nm})^{19}$ whereas these two granule types have similar centrifugation densities (1.22). Similarly secretin granules have a diameter of $250 \mathrm{~nm}^{2}$ and high modal density of 1.24 and motilin a diameter of $180-190 \mathrm{~nm}^{20}$ and density 1.20. However, in view of the fact that granule size depends on the fixation procedure employed, this lack of correlation is not surprising.

The data presented here are derived from jejunal biopsies taken from fasting subjects but clearly these techniques are readily applicable to other situations and other tissues. Thus it should be possible to study the dynamic changes in granule density in response to physiological stimuli. Similarly, possible granule alteration occurring in diseased states of the gut can also be readily studied. In view of the existence of different molecular forms of some of the gut hormones, in particular gastrin ${ }^{21}$ and enteroglucagon, ${ }^{22}$ these techniques have provided a unique opportunity to assess whether they are stored as single or multiple granules.

We thank Mr P White for expert technical assistance and Mrs R Greensted for preparing the manuscript. 
This work was supported in part by the generosity of the MRC and the Wellcome Foundation. Human serum albumin was a kind gift of the Lister Institute, Blood Products Laboratory.

\section{References}

${ }^{1}$ Besterman HS, Bloom SR, Sarson DL et al. Gut hormone profile in coeliac disease. Lancet I; 1978: 785-8.

${ }^{2}$ Solcia E, Polak JM, Pearse AGE et al.Lausanne 1977 Classification of gastroenteropancreatic endocrine cells In: Bloom S R, ed. Gut hormones. Edinburgh and London: Churchill Livingstone. 1978: 40-48.

${ }^{3}$ Peters TJ, Jones PE, Wells G. Analytical subcellular fractionation of jejunal biopsy specimens: enzyme activities, organelle pathology and response to gluten withdrawal in patients with coeliac disease. Clin Sci Mol Med 1978; 55: 285-92.

${ }^{4}$ Peters TJ. Analytical subcellular fractionation of jejunal biopsy specimens: methodology and characterization of the organelles in normal tissues. Clin Sci Molec Med 1976; 51 : 557-74.

${ }^{5}$ Bloom SR, Mitznegg P, Bryant MG. Measurement of human plasma motilin. Scand J Gastroenterol 1976; 11 Suppl. 39, 47-52.

${ }^{6}$ Russell RCG, Bloom SR, Fielding LP, Bryant MG. Current problems in the measurement of gastrin release. A reproducible measure of physiological gastrin release. Postgrad Med J 1976; 52: 645-50.

${ }^{7}$ Häcki WH, Bloom SR, Mitznegg P, et al. Plasma secretin and pancreatic bicarbonate response to exogenous secretin in man. Gut 1977; 18: 191-5.

${ }^{8}$ Bryant MG, Bloom SR. Distribution of the gut hormones in the primate intestinal tract. Gut 1979; 20: 653-9.

${ }^{9}$ Mitchell SJ and Bloom SR. Measurement of fasting and postprandial plasma VIP in man. Gut 1978; 19: 1043-48.

${ }^{10}$ Holohan KN, Murphy RF, Flanagan RW, Buchanan $\mathrm{KD}$, Elmore DT. Enzymic iodination of the histidyl residue of secretin. A radioimmunoassay of the hormone. Biochim Biophys Acta 1973; 322: 178-80.
${ }^{11}$ Hunter WM, Greenwood FC. Preparation of iodine-131 labelled human growth hormone of high specific activity. Nature 1962; 194: 495-496.

${ }^{12}$ Lowry OH, Rosebrough NJ, Farr AL, Randall RJ. Protein measurement with the Folin-phenol reagent. J Biol Chem 1951; 193: 265-75.

${ }^{13}$ Hiraoka T, Glick D. Studies in histochemistry. LXXI. Measurement of protein in milligram amounts by quenching of fluorescence dye. Anal Biochem 1963; 5: 497-504.

${ }^{14}$ Fiddes IJS, Trotman CNA. Secretin-like activity in subcellular fractions of chicken intestinal mucosa. $J$ Endocrinol 1974; 63: 239-245.

${ }^{15}$ Track NS, Creutzfeldt C, Funge U, Creutzfeldt W. Gastrin turnover in gastrinoma tissue: in vitro incubation subcellular fraction and mololayer culture studies. In Thompson JC, ed. Gastrointestinal hormones, Austin: University of Texas Press, 1975: 403-24.

${ }^{16}$ Bryant MG, Bloom SR, Polak JM, Albuquerque RH, Modlin IM, Pearse AGE. Possible dual role for vasoactive intestinal peptide as gastrointestinal hormone and neurotransmitter substance. Lancet 1976; i: 991-3.

${ }^{17}$ Larsson L-I, Fahrenkrug J, Schaffalitzky de Muckadell O, Sundler F, Håkanson R, Rehfeld JF. Localization of vasoactive intestinal peptide (VIP) to central and peripheral neurones. Proc Natl Acad Sci (USA) 1976; 73: 3197-200.

${ }^{18}$ Giachetti A, Rosenberg RM, Said SI. Vasoactive intestinal polypeptide in brain synaptosomes. (Letter.) Lancet 1976; 2: 741-42.

${ }^{19}$ Buchan AMJ, Polak JM, Solcia E, Pearse AGE. Localisation of intestinal gastrin in a distinct endocrine cell type. Nature $1979 ; 277$ : 138-40.

${ }^{20}$ Buchan AMJ, Polak JM. Classification of the human gastroenteropancreatic endocrine cells. Investigative and cellular pathology (In press).

${ }^{21}$ Rehfeld JF, Stadil F. Gelfiltration studies on immunoreactive gastrin in serum from Zollinger-Ellison patients. Gut 1973; 14: 369-73.

${ }^{22}$ Kuku SF, Jaspan JB, Emmanouel DS, Zeidler A, Katz AI, Rubenstein AH. Heterogeneity of plasma glucagon: circulating components in normal subjects and patients with chronic renal failure. $J$ Clin Invest 1976; 58: 742-50. 